Original article

\title{
The role of amino acid arginine and nitric oxide system in implementing cardioprotective effect of non-opioid analogue of leu-enkephalin in newborn albino rats after intrauterine hypoxia
}

\author{
Elena N. Sazonova ${ }^{1,2}$, Olga A. Lebed'ko ${ }^{1,2}$, Natalya A. Tsymbalist ${ }^{1}$, Ilya A. Gusev ${ }^{1}$, \\ Elena Yu. Samarina ${ }^{1}$, Yulia B. Malofey ${ }^{1}$ \\ ${ }^{1}$ Far Eastern State Medical University, Khabarovsk, Russia \\ ${ }^{2}$ Khabarovsk Branch of the Far Eastern Scientific Center for Respiratory Physiology \& Pathology - Research Institute of Maternal and Child \\ Health Protection, Khabarovsk, Russia
}

Received 7 September 2020, Revised 11 October 2020, Accepted 9 November 2020

(C) 2020, Sazonova E.N., Lebed'ko O.A., Tsymbalist N.A., Gusev I.A., Samarina E.Yu., Malofey Yu.B.

(C) 2020, Russian Open Medical Journal

\begin{abstract}
Objective - to evaluate the role of the amino acid arginine in the structure of the non-opioid analogue of leu-enkephalin (NALE) and the involvement of the nitric oxide system in the implementation of its cardioprotective effect in newborn albino rats subjected to intrauterine hypoxia.

Material and Methods - Pregnant female rats were subjected daily to 4-hour hypobaric hypoxia (oxygen partial pressure - $65 \mathrm{~mm} \mathrm{Hg}$ ) on days 15-19 of their gestation. The 7-day-old offspring of hypoxified female rats were examined. The progeny of intact animals served the control. We studied body and heart weights; activity of proliferative processes and autophagy in the myocardium of subendocardial parts of the left ventricle, expressed via the immunohistochemical detection of Ki-67 and Beclin-1 proteins, respectively; karyometric and nucleolometric indicators of cardiomyocytes (CMC); intensity of free radical processes in the tissues of the heart by chemiluminescence parameters. Correction of post-hypoxic changes in newborn rats was carried out by intraperitoneal injection of two peptides (Phe-D-AlaGly-Phe-Leu-Arg - non-opioid analogue of leu-enkephalin, or NALE, and Phe-D-Ala-Gly-Phe-Leu-Gly - G peptide) daily from day 2 through day 6 of their lives at a dose of $100 \mu \mathrm{g} / \mathrm{kg}$. To assess the involvement of the nitric oxide system in the implementation of the NALE effects, the NO synthase inhibitor - N-nitro-L-arginine methyl ester (L-NAME) was additionally administered at a dose of $50 \mathrm{mg} / \mathrm{kg}$.

Results - Intrauterine hypoxia led to a decrease in body weights of 7-day-old animals, an increase in the number of CMC expressing the Beclin-1 protein, reduction in the size of $\mathrm{CMC}$ nuclei, activation of free radial oxidation, and a decrease in antiradical protection in the heart tissues. The administration of NALE to newborn animals, subjected to intrauterine hypoxia (IUH), normalized their body weight and size of the CMC nuclei, and partially corrected changes in Beclin-1 expression and in chemiluminescence parameters. In 7-day-old animals, subjected to IUH and neonatal administration of NALE and L-NAME, a lower body weight was observed than in the control. Against the background of nitric oxide blockade, the antioxidant effect of NALE diminished, but the corrective effect of NALE on the karyometric index and Beclin-1 expression remained. G peptide, which differs from NALE by the substitution of the C-terminal amino acid Arg for the amino acid Gly, exhibited a corrective effect similar to NALE on the consequences of IUH.

Conclusion - Administration of NALE and G peptides to newborn albino rats after IUH has a pronounced cardioprotective effect. The mechanisms of the NALE peptide effects are, in part, associated with the activation of the NOS-NO system. However, the affinity of this peptide for opioid-like receptors may be of greater importance.
\end{abstract}

Keywords: leu-enkephalin analogues, intrauterine hypoxia, cardiomyocytes, nitric oxide.

Cite as Sazonova EN, Lebed'ko OA, Tsymbalist NA, Gusev IA, Samarina EYu, Malofey YuB. The role of amino acid arginine and nitric oxide system in implementing cardioprotective effect of non-opioid analogue of leu-enkephalin in newborn white rats after intrauterine hypoxiat. Russian Open Medical Journal 2020; 9: e0404.

Correspondence to Elena N. Sazonova. Phone: +79242063463. E-mail: sazen@mail.ru.

\section{Introduction}

The non-opioid analogue of leu-enkephalin (NALE) - the peptide Phe-D-Ala-Gly-Phe-Leu-Arg - exhibits a pronounced cardioprotective effect, when administered to newborn albino rats, subjected to intrauterine hypoxia (IUH) [1]. NALE is characterized by cytoprotective and antioxidant effects in vitro [2]. This peptide has no affinity for opioid receptors due to the substitution of the N-terminal amino acid Tyr in the structure of leu-enkephalin for the amino acid Phe [3]. In this regard, the mechanisms of NALE effects remain uncertain. A hypothesis was proposed about the significant role of the C-terminal amino acid arginine in the realization of its effects. It is known that peptides containing the amino acid arginine at the terminal position can act as inducers of nitric oxide (NO) synthesis due to the release of the NO synthase (NOS) substrate [4]. The NOS-NO system is an important pathogenetic element of cardioprotection [5]. 
Table 1. Distribution of animals by study type

\begin{tabular}{lccccc}
\hline Sample size, $n$ & Control & IUH & IUH+NALE & IUH+NALE + I-NAME & IUH $+G$ \\
\hline Total & 35 & 27 & 34 & 27 & 31 \\
\hline $\begin{array}{l}\text { Chemiluminescent } \\
\text { studies }\end{array}$ & 15 & 10 & 15 & 12 & 15 \\
Gravimetric analysis, & 20 & 17 & 19 & 15 & 16 \\
$\begin{array}{l}\text { of which } \\
\text { morphological studies }\end{array}$ & 10 & 8 & 10 & 10 & 10 \\
\hline
\end{tabular}

The objective of our study was to assess the role of the amino acid arginine in the structure of NALE and involvement of the nitric oxide system into implementation of the peptide cardioprotective effect in newborn albino rats subjected to IUH.

\section{Material and Methods}

\section{Study subjects}

The experiment used three-month-old pregnant albino female Wistar rats $(n=20)$ and their offspring $(n=154)$. The animals were kept in a vivarium at a temperature of $22-24^{\circ} \mathrm{C}$ and with access to food and water ad libitum. The animals were fed with standard pelleted food for laboratory rodents.

\section{Test substances}

We used peptides synthesized by the Limited Liability Company Almabion (RF); control of the peptide purity (95\%) was provided by high-performance liquid chromatography (HPLC) analysis and mass spectrometry:

1) The peptide Phe-D-Ala-Gly-Phe-Leu-Arg is a structural analogue of leu-enkephalin with three structural modifications: (1) the addition of the C-terminal amino acid Arg; (2) replacement of the amino acid Gly in the second position of the amino acid chain with amino acid D-Ala to increase the resistance of the peptide to the action of endopeptidases [6]; (3) replacement of the $\mathrm{N}$ terminal amino acid Tyr with amino acid Phe. Since the $\mathrm{N}$-terminal amino acid Tyr is crucial for the interaction of opioid peptides with specific receptors [3], the Phe-D-Ala-Gly-Phe-Leu-Arg peptide is incapable of binding to opioid receptors and was named a nonopioid analogue of leu-enkephalin (NALE).

2) The peptide Phe-D-Ala-Gly-Phe-Leu-Gly is a structural analogue of the NALE peptide and differs from the latter by amino acid Gly replacing the C-terminal amino acid Arg. Due to this replacement, this peptide was called $\mathrm{G}$ peptide.

Besides, N-nitro-L-arginine methyl ester (L-NAME) (Sigma Aldrich, USA), a non-selective inhibitor of nitric oxide synthase, was used in our study [7].

\section{Experimental design}

For the experiment, three-month-old female rats were placed to sexually mature male rats in a ratio of $4: 1$. The onset of pregnancy was recorded by the presence of sperm in vaginal smears. To simulate IUH, pregnant female rats were subjected to 4-hr hypoxic exposure daily over 15 to 19 days of gestation. The animals were placed in an experimental hypobaric chamber, in which the pressure was reduced to $310 \mathrm{~mm} \mathrm{Hg}$, which corresponded to conditions at an elevation of $7000 \mathrm{~m}$ above sea level. In this case, the partial pressure of oxygen was $65 \mathrm{~mm} \mathrm{Hg}$. The 7-day-old offspring of hypoxified female rats were examined, while the progeny of intact animals considered the control.
The following five experimental groups of animals were formed:

1) Control group ( $n=35$ ): the offspring of intact (not exposed to hypoxia) female rats, who were administered daily $0.1 \mathrm{ml}$ of isotonic sodium chloride solution intraperitoneally from day 2 to day 6 of their lives;

2) IUH group ( $n=27)$ : the offspring of hypoxified female rats, who were administered daily $0.1 \mathrm{ml}$ of isotonic sodium chloride solution intraperitoneally from day 2 to day 6 of their lives;

3) IUH+NALE group $(n=34)$ : the offspring of hypoxified female rats, who were administered daily NALE peptide intraperitoneally at a dose of $100 \mu \mathrm{g} / \mathrm{kg}$ in $0.1 \mathrm{ml}$ of solvent (isotonic sodium chloride solution) from day 2 to day 6 of their lives;

4) IUH+NALE+ L-NAME group ( $n=27)$ : offspring of hypoxified female rats, who were administered daily NALE peptide at a dose of $100 \mu \mathrm{g} / \mathrm{kg}$ in $0.1 \mathrm{ml}$ of solvent (isotonic sodium chloride solution) and L-NAME at a dose of $50 \mathrm{mg} / \mathrm{kg}$ in $0.05 \mathrm{ml}$ of solvent (isotonic sodium chloride solution) intraperitoneally;

5) IUH+G peptide group ( $n=31$ ): offspring of hypoxified female rats, who received daily intraperitoneal injection of $\mathrm{G}$ peptide at a dose of $100 \mu \mathrm{g} / \mathrm{kg}$ in $0.1 \mathrm{ml}$ of a solvent (isotonic sodium chloride solution) from day 2 to day 6 of their lives.

Removal of animals from the experiment was conducted by rapid decapitation under ether anesthesia with chloroform vapor. We then we determining their body weights $(\mathrm{g})$ and absolute heart weights (mg).

In each experimental group of 7-day-old animals, some of the animals were used to extract the heart for chemiluminescence studies, while some were used for gravimetric and morphological studies (Table 1).

During morphological examination, histological topography sections (across all parts of the heart) in the amount of 12 pieces were prepared from the heart of each animal; sections were mounted four pieces for each of three glasses for three histological methods: immunohistochemical (IHC) determination of Ki-67, IHC identification of Beclin-1, and staining with silver nitrate. The unit of statistical sampling for each research method was the indicators of a single animal.

\section{Morphometric and immunohistochemical studies}

The heart was subjected to standard histological preparation with cutting paraffin sections. We used neutral $10 \%$ formaldehyde in phosphate buffer as a fixative.

To identify the nucleolus organizer regions, histological topography sections of the heart, after dewaxing, were stained with silver nitrate, according to the AgNOR method [8]. The morphometry of the nuclear-nucleolar apparatus of cardiomyocytes (CMC) was carried out on a MEKOS-C computerassisted image analyzer: the area of the $\mathrm{CMC}$ nucleus, along with the number and total area size of nucleoli in the $\mathrm{CMC}$ nucleus were estimated.

Paraffin sections of the heart $3 \mu \mathrm{m}$ thick, subject to IHC study, were mounted on glasses with an adhesive electrostatic coating SuperFrost Plus. The following antibodies were used:

i) Polyclonal antibodies to $\mathrm{Ki}-67$ protein (Cloud-Clone Corp., USA);

ii) Monoclonal antibodies to Beclin-1 protein (CloudClone Corp., USA). 
Table 2. Body and heart weights of 7-day-old albino rats in study groups ( $\mathrm{M} \pm \mathrm{SD}$ )

\begin{tabular}{lcc}
\hline Experimental groups & Body weight, $g$ & Heart weight, mg \\
\hline Control $(n=20)$ & $12.28 \pm 2.27$ & $88.40 \pm 14.29$ \\
IUH $(n=17)$ & $10.66 \pm 2.08 * p=0.04$ & $84.59 \pm 19.52 * p=0.54$ \\
IUH+NALE $(n=19)$ & $11.78 \pm 1.40 * p=0.25 \# p=0.09$ & $89.68 \pm 15.06 * p=0.870 \# p=0.48$ \\
IUH+NALE+L-NAME $(n=15)$ & $10.43 \pm 1.95 * p=0.02 \# p=0.88 \& p=0.029$ & $72.40 \pm 10.89 * p=0.001 \# p=0.046 \& p=0.03$ \\
IUH+G peptide $(n=16)$ & $11.57 \pm 1.63 * p=0.32 \# p=0.15$ & $93.31 \pm 14.83 * p=0.46 \# p=0.08$ \\
\hline
\end{tabular}

* - significance of differences with control group; \# - significance of differences with IUH group; \& - significance of differences with IUH+NALE group.

Table 3. Immunohistochemical myocardium study of 7-day-old albino rats in experimental groups (MISD)

Experimental groups

Control $(n=10)$

IUH $(n=8)$

IUH+NALE $(n=10)$

IUH+NALE+ L-NAME $(n=10)$

IUH $+\mathrm{G}$ peptide $(\mathrm{n}=10)$
Ki-67 labeling index of cardiomyocytes (\%)

$23.27 \pm 7.50$

$19.97 \pm 5.03 * \mathrm{p}=0.45$

$20.61 \pm 6.00 * p=0.43 \# p=0.87$

$16.64 \pm 6.69 * \mathrm{p}=0.07 \# \mathrm{p}=0.41 \& \mathrm{p}=0.35$

$15.23 \pm 3.78 * \mathrm{p}=0.014 \# \mathrm{p}=0.06$
Beclin-1 labeling index of cardiomyocytes (\%) $7.90 \pm 3.00$

$17.04 \pm 3.84 * \mathrm{p}=0.0001$

$14.05 \pm 1.65 * p=0.0001 \# p=0.049$

$11.96 \pm 2.52 * \mathrm{p}=0.008 \# \mathrm{p}=0.007 \& \mathrm{p}=0.06$

$11.20 \pm 3.00 * p=0.03 \# p=0.005$

* - significance of differences with control group; \# - significance of differences with IUH group; \& - significance of differences with IUH+NALE group.

Table 4. Indicators of nuclear-nucleolar apparatus in cardiomyocytes of 7-day-old albino rats in study groups (M $\pm S D$ )

\begin{tabular}{lccc}
\hline Experimental groups & Nucleus area $\left(\mu \mathrm{m}^{2}\right)$ & Total area of nucleoli $\left(\mu \mathrm{m}^{2}\right)$ & Number of nucleoli \\
\hline Control $(n=10)$ & $21.66 \pm 4.26$ & $1.875 \pm 0.474$ & $2.666 \pm 0.198$ \\
IUH $(n=8)$ & $17.20 \pm 0.74 * p=0.023$ & $1.666 \pm 0.299 * p=0.319$ & $2.717 \pm 0.288 * p=0.688$ \\
IUH+NALE $(n=10)$ & $22.48 \pm 5.85 * p=0.749 \# p=0.049$ & $2.228 \pm 0.501 * p=0.152 \# p=0.024$ & $2.949 \pm 0.333 * p=0.056 \# p=0.173$ \\
IUH+NALE+L-NAME $(n=10)$ & $22.68 \pm 3.06 * p=0.580 \# p=0.001 \& p=0.934$ & $2.194 \pm 0.507 * p=0.193 \# p=0.029 \& p=0.889$ & $2.619 \pm 0.321 * p=0.714 \# p=0.536 \& p=0.054$ \\
IUH+G peptide $(n=10)$ & $21.25 \pm 4.44 * p=0.49 \# p=0.037$ & $2.032 \pm 0.249 * p=0.422 \# p=0.026$ & $3.047 \pm 0.255 * p=0.004 \# p=0.039$
\end{tabular}

* - significance of differences with control group; \# - significance of differences with IUH group; \& - significance of differences with IUH+NALE group.

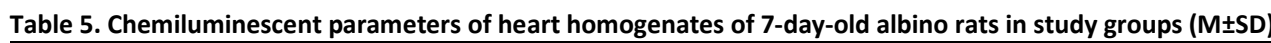

\begin{tabular}{|c|c|c|c|c|c|}
\hline $\begin{array}{l}\text { Indices measured in } \\
\text { conventional units }\end{array}$ & Control $(n=15)$ & $I U H(n=10)$ & $I U H+N A L E(n=15)$ & $I U H+N A L E+I-N A M E(n=12)$ & $I U H+G$ protein $(n=15)$ \\
\hline \multirow[b]{2}{*}{$\begin{array}{l}S_{s p} \\
\ldots \ldots\end{array}$} & \multirow[b]{2}{*}{$2.968 \pm 0.580$} & $6.168 \pm 0.951$ & $4.017 \pm 0.819$ & $5.034 \pm 0.706$ & $4.889 \pm 0.973$ \\
\hline & & $* p<0.001$ & ${ }^{*} \mathrm{p}=0.002, \# p<0.001$ & ${ }^{*} \mathrm{p}<0.001, \# p=0.010, \& p=0.004$ & ${ }^{*} \mathrm{p}<0.001, \# \mathrm{p}=0.070$ \\
\hline$S_{\text {ind1 }}$ & $7.036 \pm 1.381$ & ${ }^{*} p<0.001$ & ${ }^{*} \mathrm{p}=0.005, \# \mathrm{p}<0.001$ & $* \mathrm{p}<0.001, \# \mathrm{p}=0.008, \& \mathrm{p}=0.020$ & ${ }^{*} \mathrm{p}<0.001, \# \mathrm{p}=0.004$ \\
\hline \multirow{2}{*}{$\mathrm{H} 1$} & \multirow{2}{*}{$2.775 \pm 0.520$} & $4.896 \pm 0.939$ & $3.450 \pm 0.961$ & $4.087 \pm 0.789$ & $4.017 \pm 0.864$ \\
\hline & & ${ }^{*} p<0.001$ & ${ }^{*} \mathrm{p}=0.036, \# \mathrm{p}=0.003$ & $* \mathrm{p}<0.001, \# \mathrm{p}=0.059, \& \mathrm{p}=0.090$ & ${ }^{*} \mathrm{p}<0.001, \# \mathrm{p}=0.040$ \\
\hline$S_{\text {ind2 }}$ & $18.410 \pm 2.567$ & ${ }^{*} p<0.001$ & $* \mathrm{p}<0.001, \# \mathrm{p}<0.001$ & $* \mathrm{p}<0.001, \# \mathrm{p}<0.001, \& \mathrm{p}=0.007$ & $* \mathrm{p}<0.001, \# \mathrm{p}<0.001$ \\
\hline \multirow{2}{*}{$\mathrm{H} 2$} & \multirow{2}{*}{$13.293 \pm 2.320$} & $31.301 \pm 3.861$ & $19.204 \pm 3.386$ & $23.889 \pm 3.605$ & $23.377 \pm 3.682$ \\
\hline & & ${ }^{*} p<0.001$ & ${ }^{*} p<0.001, \# p<0.001$ & ${ }^{*} p<0.001, \# p=0.006, \& p=0.005$ & ${ }^{*} p<0.001, \# p<0.001$ \\
\hline
\end{tabular}

* - significance of differences with control group; \# - significance of differences with IUH group; \& - significance of differences with IUH+NALE group; $\mathrm{S}_{\mathrm{sp}}-$ light intensity over 1 min of spontaneous chemiluminescence; $\mathrm{S}_{\text {ind } 1}$ - light intensity over 2 min of Fe ${ }^{2+}$-induced chemiluminescence; $\mathrm{H} 1$ - maximum amplitude of a fast flash of $\mathrm{Fe}^{2+}$-induced luminescence; $\mathrm{S}_{\text {ind } 2}$ - light intensity over 2 min of $\mathrm{H}_{2} \mathrm{O}_{2}$-induced luminol-dependent chemiluminescence; $\mathrm{H} 2$ - maximum of the amplitude of $\mathrm{H}_{2} \mathrm{O}_{2}$-induced luminol-dependent luminescence.

Primary antibodies were diluted with Dako Antibody Diluent solution (Dako North America Inc., USA): Ki-67 to the concentration of $8 \mu \mathrm{g} / \mathrm{ml}$, Beclin-1 to the concentration of $5 \mu \mathrm{g} / \mathrm{ml}$. Pre-dewaxed sections were placed in citrate buffer (Cloud-Clone Corp., USA), and high-temperature antigen unmasking was performed in the MILESTONE Histos 5 Rapid Microwave Histoprocessor for $19 \mathrm{~min}$ at $98{ }^{\circ} \mathrm{C}$. Further processing of the sections was carried out, using a polyvalent imaging system, based on the biotin-streptavidin-peroxidase complex (Leica Biosystems, Germany). To block endogenous peroxidase, the sections were incubated with a peroxidase block for 10 minutes; treated with primary antibodies for 30 minutes, secondary antibodies for 20 minutes, polymer solution for 30 minutes, and freshly prepared $D A B$ solution for 5 minutes. At the final stage of the reaction, the sections were counterstained with hematoxylin. Preparations without incubation in primary antibodies - but in full compliance with the rest of the protocol steps - served a negative control.

Labeled CMCs were counted under light microscopy with a $15 \times 100$ microscope magnification in the subendocardial zone of the left ventricle, based on viewing at least 500 cells. The proportion of proliferating $\mathrm{CMC}$ was estimated by specific IHC staining with antibodies to the Ki-67 protein. By specific IHC staining with antibodies to the Beclin-1 protein of the cell cytoplasm, the proportion of CMC in the state of autophagy was estimated [9].

\section{Chemiluminescence study}

We employed the chemiluminescence method (CML) to analyze the activity of free radical oxidation in heart homogenates of 7-day-old animals. CML was recorded on an LS-50B luminescence spectrometer (Perkin Elmer), following the 
previously described procedures [10]. The signal was standardized using the built-in FinLab software. The following parameters were determined: $\mathrm{S}_{\mathrm{sp}}$ - light intensity over $1 \mathrm{~min}$ of spontaneous CML; $\mathrm{H} 1$ - maximum amplitude of a fast flash of $\mathrm{Fe}^{2+}$-induced luminescence; $\mathrm{S}_{\text {ind1 }}$ - light intensity over 2 min of $\mathrm{Fe}^{2+}$-induced $\mathrm{CML} ; \mathrm{H} 2$ - maximum of the amplitude of $\mathrm{H}_{2} \mathrm{O}_{2}$-induced luminoldependent luminescence; $\mathrm{S}_{\text {ind2 }}$ - light intensity over 2 min of $\mathrm{H}_{2} \mathrm{O}_{2}$ induced luminol-dependent chemiluminescence. The $\mathrm{CML}$ intensity was expressed in relative units.

\section{Statistical data processing}

Statistical processing of experimental data was carried out using the Statistica 6.0 program. After confirming the normality of the distribution of variation series, the values of arithmetic mean (M) and standard deviation (SD) were determined. Comparison among groups was conducted, using the Student's t-test. Differences were considered significant at $p<0.05$.

\section{Results}

Effect of intrauterine hypoxia on the studied heart indicators in 7-day-old animals

Hypoxic exposure from day 15 through day 19 of gestation led to a change in the state of 7-day-old offspring of albino rats. A decrease in the body weight of animals by $13.2 \%$ was recorded. The heart weight of 7-day-old rats of the IUH group did not statistically significantly differ from the control value (Table 2).

When analyzing the Ki-67 labeling index of $\mathrm{CMC}$ nuclei in animals of the IUH group, a decrease in the number of proliferating cells by $14.18 \%$ was revealed (Table 3). However, the observed change was not statistically significant. IUH significantly (twice as much) increased the proportion of CMCs, expressing Beclin-1 protein (Table 3), which reflected a pronounced activation of the cell autophagy process. Morphometric studies of the nuclear-nucleolar apparatus of the CMC in IUH group animals did not register significant changes in the number and size of nucleoli, but exposed a significant decrease by $20.6 \%$ in the size of cell nuclei (Table 4).

A chemiluminescent study of heart homogenates in experimental animals showed a 2.1-fold increase in the intensity of free radical processing $\left(\mathrm{S}_{\mathrm{sp}}\right)$; an increase in the rate of forming peroxide radicals $\left(\mathrm{S}_{\text {ind1 } 1}\right)$ by 1.94 times; increase in the content of lipid hydroperoxides $(\mathrm{H} 1)$ by 1.76 times. At the same time, the peroxide resistance of the substrate and the activity of the antioxidant defense system significantly decreased, as evidenced by the increase in $\mathrm{H} 2$ index by 2.35 times and a two-fold increase in $\mathrm{S}_{\text {ind2 }}$ (Table 5).

Thus, the IUH effect led to activation of the autophagy process in the myocardium of experimental 7-day-old animals and a decrease in size of the $\mathrm{CMC}$ nuclei, which probably reflected the state of cellular stress. The registered morphological changes were recorded against the background of pronounced oxidative stress at the tissue level. Similar changes in the redox status of the myocardium and in the state of the $\mathrm{CMC}$ in newborn animals after severe IUH were previously detected by us [1]

Effect of neonatal administration of the NALE peptide on indicators of 7-day-old albino rats after intrauterine hypoxia

The introduction of NALE peptide to experimental animals, subjected to IUH, from day 2 through day 6 of their lives corrected a number of deviations. There was a normalization of the body weight: this indicator in the IUH+NALE group did not differ significantly from the control (Table 2). The morphometric parameters of the CMC nuclear-nucleolar apparatus in animals of this experimental group also did not differ from the control parameters. At the same time, the area of the nuclei and the total area of the nucleoli in the CMC of the animals in the IUH+NALE group significantly exceeded those of the IUH group (Table 4). The proportion of CMCs, expressing Beclin-1 protein in the IUH+NALE group remained significantly higher than control value, but was significantly (by $17.5 \%$ ) lower than in the IUH group (Table 3 ). A similar pattern was observed in the CML study of heart homogenates in animals of the IUH+NALE group: the parameters, characterizing the severity of oxidative stress, were represented by numerically smaller values than in the IUH group - by $29.5 \%$ $38.7 \%$ (Table 5). Consequently, the introduction of NALE peptide in the neonatal period to animals after IUH was able to partially correct negative changes in the myocardium and the body as a whole. Our findings are consistent with the previously identified protective effects of the NALE peptide for the CMC of white rats, exposed to severe IUH [1].

Effect of neonatal administration of the NALE peptide against the background of inhibiting NO synthesis on indicators of 7-dayold albino rats after intrauterine hypoxia

Exposure of IUH-subjected animals to NALE peptide against the background of nitric oxide synthesis blockade did not correct changes in animal body weights. The body weights in the IUH+NALE+L-NAME group did not differ from those in IUH group, and were significantly lower than the body weights of control animals (by $15.1 \%$ ) and IUH+NALE group (by $11.5 \%$ ). Besides, in the animals of this group, we detected a significant decrease in the heart mass, compared with control (by 18.1\%), IUH (by 14.4\%) and IUH+NALE groups (by 19.3\%) (Table 2). The decrease in heart weight under conditions of nitric oxide synthesis blockade was possibly due to a decline in the proliferative activity of CMC: in animals of this group, wee observed a pronounced tendency to a reduction in the proportion of $\mathrm{CMC}$, expressing $\mathrm{Ki}-67$ (by $28.5 \%$, compared with the control) (Table 3). Animals of the IUH+NALE+LNAME group were also characterized by a significantly augmented proportion of $\mathrm{CMC}$, expressing Beclin-1, compared with the control (by $51.3 \%$ ). At the same time, the proportion of CMCs, showing staining with the autophagy marker, in this experimental group was significantly (by $14.9 \%$ ) lower than the same indicator in the IUH group (Table 3 ). The sizes of the nuclei and nucleoli of the CMC in the IUH+NALE+L-NAME group did not differ from the control values, but were significantly higher than those in the IUH group by $31.9 \%$ and $31.7 \%$, respectively.

The indices of free radical oxidation in the heart homogenates of the animals from IUH+NALE+L-NAME group were significantly (by $47.3 \%-79.7 \%$ ) higher than those of the control group; and also, by $13.5 \%-25.35 \%$ higher than the indicators of the IUH+NALE group. However, four out of five CML parameters remained significantly lower than those of the IUH group.

Thus, the introduction of an inhibitor of the nitric oxide synthesis, L-NAME, partially neutralized the positive effect of the NALE peptide on the condition of experimental animals subjected to IUH: the animals of the IUH+NALE+L-NAME group retained posthypoxic decrease in body weights; there was a more pronounced, in comparison with the IUH+NALE group, activation of free radical 
oxidation. At the same time, the blockade of nitric oxide synthesis did not completely eliminate the cardioprotective effect of NALE.

\section{Effect of neonatal administration of $G$ protein on indicators of 7-day-old albino rats after intrauterine hypoxia}

The introduction of $\mathrm{G}$ peptide to IUH-subjected experimental animals from day 2 through day 6 of their lives caused effects similar to those of the NALE peptide. In animals of the IUH+G experimental group, we observed the absence of significant differences from the control in body and heart weights (Table 2), as well as in the size of the CMC nuclei and nucleoli (Table 4). In this group, there was a significant $14.3 \%$ increase in the number of $\mathrm{CMC}$ nucleoli in comparison with the control, in conjunction with a $34.6 \%$ decrease in the proportion of cells, expressing $\mathrm{Ki}-67$ protein. The proportion of CMC with an IHC marker of autophagy in the $\mathrm{IUH}+\mathrm{G}$ group, as well as the parameters of free radical oxidation, were significantly smaller than the corresponding parameters of the IUH group, although they remained significantly higher than in control group.

Thus, the introduction of the NALE analogue - $G$ peptide - led to a partial correction of the studied post-hypoxic changes in the body of 7-day-old animals. The effects of $G$ peptide were similar to those of NALE peptide.

\section{Discussion}

IUH causes negative changes in the heart condition both in the neonatal period and in subsequent ontogenetic development stages. In experimental animals subjected to IUH, hypoplasia of the heart walls, a reduction in the CMC number in combination with their hypertrophy were described [11-13]. A decrease in the number of $\mathrm{CMC}$ is a consequence of their reduced proliferative activity and augmented apoptosis. An early exit of CMC from the cell cycle with premature differentiation and an increase in the proportion of binuclear CMC was revealed [11]. The transition of CMC from mononuclear to binuclear phenotype occurs vis incomplete cytokinesis during mitosis. The resulting binuclear cells are terminally differentiated and, hence, they are unable to proliferate [14]. These changes have epigenetic mechanism: an increased DNA methylation [15]. All these post-hypoxic changes significantly reduce the structural reserve of the heart for subsequent functioning and make the body more vulnerable to cardiac catastrophes at the later stages of ontogenesis.

In our previous publications, we showed ongoing reduction both in body weight and in heart weight, along with a decrease in the DNA-synthetic CMC activity and decline in the number of nucleoli in the $\mathrm{CMC}$ nuclei of newborn albino rats that underwent severe IUH $[1,16]$. The results of the present study, in general, confirmed the nature of post-hypoxic changes in the myocardium of newborn experimental animals. At the same time, in this study, we identified a number of differences from the earlier obtained results. For example, in this experiment, we recorded a decrease in the body weight of animals, but did not reveal significant changes in the heart weight. The cause of less pronounced changes, apparently, lies in less severe hypoxic effect (expressed as analogue to occurring at $7000 \mathrm{~m}$ above sea level versus $9000 \mathrm{~m}$ in our previous experiments). It is known that, in IUH conditions, the body protects its vital organs (heart, brain) by redistribution and centralization of blood circulation; therefore, the decrease in heart mass lags behind the reduction in body weight significantly [11]. Also, this fact probably explains the absence of a significant change in the proliferative activity of $\mathrm{CMC}$ (Ki-67 labeling index). Another feasible explanation could root in a different methodological approach, used by us to assess the proliferative activity of CMC. Previously, we recorded the DNA-synthetic CMC activity, using autoradiography with ${ }^{3} \mathrm{H}$-tritium-labeled thymidine, which made it possible to estimate the amount of $\mathrm{CMC}$ in the $\mathrm{S}$ period of the cell cycle. The method of IMC assessment of Ki-67 labeled $\mathrm{CMC}$ reveals the entire proliferating pool of cells, with the exception of cells in the $\mathrm{GO}$-phase.

In 7-day-old experimental animals subjected to IUH manifestations of oxidative stress at the organ level were recorded, which were accompanied by a pronounced increase in the expression of the Beclin-1 protein. This protein performs the most important functions in the autophagic process in the $\mathrm{CMC}$ and highly correlates with the cell apoptosis level [9]. It is known that activation of autophagy is a universal cell response to damaging influences [17]. Oxidative stress with generation of significant amounts of reactive oxygen species is the main stimulus for autophagy [18]. An increased formation of Beclin-1 in the CMC was shown in ischemia-reperfusion myocardial lesions. In this case, stimulation of autophagy is provided by reactive oxygen species [19]. A reduction in the size of nuclei in experimental animals under these conditions, apparently, reflects the pronounced cellular stress of the CMC. A decrease in the size of the $\mathrm{CMC}$ nuclei is detected after cold stress in rats due to myocardial ischemia [20].

Administering NALE to IUH-subjected animals in the neonatal period (on a daily basis - from day 2 through day 6 of their lives) reduces the severity of negative changes in their bodies. Previously [1], we have reported the ability of NALE to reduce negative posthypoxic changes in gravimetric parameters and free-radical processes, as well as to normalize the proliferative activity of $\mathrm{CMC}$ and the state of nucleoli in the CMC nuclei of 7-day-old white rats, subjected to severe IUH. In the present study, we demonstrated NALE-induced normalization of the body weight and CMC karyometric index in experimental animals. Compared with the indicator values for the IUH group, the severity of oxidative stress at the tissue level and the proportion of CMC, expressing Beclin-1, significantly decreased. According to the literature sources, a decline in Beclin-1 expression reduces CMC autophagy, caused by ischemia-reperfusion injury, and improves cell survival [21]. Therefore, in this experimental model, we were able to confirm the cardioprotective effect of the NALE peptide.

Bearing in mind the structural features of the NALE peptide, depriving it of its affinity for opioid receptors, the issue of the possible mechanisms of the peptide's effect on cells remains relevant. The C-terminal amino acid Arg in the NALE molecule can cause the activation of the NOS-NO system, lead to an increase in the activity of constitutive NOS, and provide a cytoprotective effect due to generation of NO. There is some evidence that cardioprotection in conditions of myocardial ischemia is associated with augmented NOS induction [22].

Accordingly, the blockade of nitric oxide synthesis can neutralize the manifestations of the NALE peptide cardioprotective effect. To test this hypothesis, we evaluated NALE effects on the studied parameters of the heart in 7-day-old white rats who underwent IUH under conditions of NOS blockade with a non-selective inhibitor - LNAME. Under these conditions, we discovered the absence of a corrective effect of NALE on the body weight of the experimental animals, along with a slight decline in the its antioxidant effect. No 
statistically significant effect of the NOS-NO system blockade on the amount of CMC with manifestations of autophagy and the nuclearnucleolar apparatus of the CMC was observed. Therefore, we concluded that blockade of nitric oxide synthesis only partially neutralized the effects of NALE.

At the same time, in the IUH+NALE+L-NAME group versus control animals, a significant reduction in heart mass and a pronounced tendency towards a decrease in the index of Ki-67labeled CMC nuclei drew our attention. Apparently, this was due to the intrinsic effect of L-NAME on the myocardium. Administration of L-NAME increases the production of reactive oxygen species in the heart [23]. Administration of L-NAME to rats with ischemia-reperfusion myocardium injury activates apoptotic death of CMC [24]. Therefore, an important addition to the analysis of the amino acid Arg role in the structure of NALE was introduced by the results of an experiment on the effect of the NALE analogue, modified in the C-terminal amino acid, called G peptide (Phe-D-Ala-Gly-Phe-Leu-Gly), on neonatal rats after IUH.

With regard to gravimetric parameters (body weight) and $\mathrm{CMC}$ nucleometry, the administration of $G$ peptide completely neutralized post-hypoxic changes. The peptide induced a significant (relative to the control) decrease in the Ki-67 labeling index of CMC nuclei and an increase in the number of nucleoli, which could indirectly indicate the acceleration of the processes of CMC differentiation. $\mathrm{G}$ peptide had a pronounced antioxidant effect, only slightly less than the analogous effect of the NALE peptide, and significantly reduced the number of CMCs, expressing the autophagy marker - Beclin-1 protein. Thus, G peptide also exhibited a cardioprotective effect in animals that underwent IUH. Analyzing possible mechanisms of the $G$ peptide effect on heart, we should emphasize its pronounced structural analogy with the $\mathrm{N}$-terminal fragment of the endogenous peptide nociceptin and, therefore, possible affinity of $G$ peptide for opioid-like receptors, which are specific nociceptin receptors. Affinity for opioid-like receptors is due to the peptide fragment Phe-X-Gly-Phe [25], which is present in the structures of both NALE and G peptides. Opioid-like receptors are present on the CMC membrane [26] and are likely to be involved in the cardiotropic properties of NALE and G peptide.

\section{Conclusion}

Administering a non-opioid analogue of leu-enkephalin (PheD-Ala-Gly-Phe-Leu-Arg) to newborn albino rats, subjected to intrauterine hypoxia, has a pronounced cardioprotective effect. The mechanisms of the NALE peptide effects are, partially, associated with the activation of the NOS-NO system. However, the affinity of the peptide for opioid-like receptors may be of greater importance.

\section{Conflict of interest}

The authors declare that there is no conflict of interest.

\section{Acknowledgements}

The study was conducted with the financial support by the Russian Foundation for Basic Research within the framework of scientific project No. 19-015-00020.

\section{Ethical approval}

The experiments were guided by the requirements of the 'European Convention for the Protection of Vertebrate Animals Used for Experimental and Other Scientific Purposes' (Strasbourg, 1986) and 'Principles of Good
Laboratory Practice' (Federal Standard No. 33044-2014). The permission of the Ethical Committee at the Far Eastern State Medical University, Ministry of Healthcare of the Russian Federation was obtained for the study (Protocol No. 2 of February 5, 2019).

\section{References}

1. Sazonova EN, Tsimbalist NA, Kaplieva OV, Lebed'ko OA. The influence of non-opiate analogue of leu-enkephalin to the cardiac consequences of intrauterine hypoxia of albino rats. Russian Open Medical Journal 2019; 8: e0401. http://doi.org/10.15275/rusomj.2019.0401.

2. Sazonova EN, Lebed'ko OA, Denisyuk GA, Zhmerenetskiy KV, Dobrykh VA. Cytoprotective effect of non-opioid leu-enkephalin analogue in primary culture of pulmonary fibroblasts in oxidative stress. Kazan Medical Journal 2019; 100(1): 153-157. Russian. http://doi.org/10.17816/KMJ2019-153.

3. Sasaki Y, Ambo A. 2',6'-dimethylphenylalanine: a useful aromatic amino acid surrogate for Tyr or Phe residue in opioid peptides. Int $J$ Med Chem 2012; 2012: 498901 http://doi.org/10.1155/2012/498901.

4. Yang XD, Ma JY, Barger MW, Ma JK. Transport and utilization of arginine and arginine-containing peptides by rat alveolar macrophages. Pharm Res 2002; 19(6): 825-831. http://doi.org/10.1023/a:1016132200104.

5. Totzeck M, Hendgen-Cotta UB, Rassaf T. Nitrite-Nitric Oxide Signaling and Cardioprotection. Adv Exp Med Biol 2017; 982: 335-346. http://doi.org/10.1007/978-3-319-55330-6 18.

6. Zhivotova EYu, Lebedko OA, Timoshin SS. Effect of leu-enkephalin analogues on the process of dna synthesis and free radical oxidation in gastric mucous lining of albino rats. Far East Medical Journal 2012; (1) 109-112. Russian. https://www.elibrary.ru/item.asp?id=17390698.

7. Pfeiffer S, Leopold E, Schmidt K, Brunner F, Mayer B. Inhibition of nitric oxide synthesis by NG-nitro-L-arginine methyl ester (I-NAME): requirement for bioactivation to the free acid, NG-nitro-L-arginine. $\mathrm{Br} J$ Pharmacol 1996; 118(6): 1433-1440. http://doi.org/10.1111/j.14765381.1996.tb15557.x.

8. Trerè D. AgNOR staining and quantification. Micron 2000; 31(2): 127 131. https://doi.org/10.1016/s0968-4328(99)00069-4.

9. Maejima $\mathrm{Y}$, Isobe $\mathrm{M}$, Sadoshima J. Regulation of autophagy by Beclin 1 in the heart. J Mol Cell Cardiol 2016; 95: 19-25. https://doi.org/10.1016/j.yjmcc.2015.10.032.

10. Lebedko OA, Ryzhavskii BYa, Zadvornaya OV. Free radical status of neocortex of albino rats and its modification by exogenous testosterones derivates. Far East Medical Journal 2011; (4): 95-99. Russian. https://www.elibrary.ru/item.asp?id=17273646.

11. Bae S, Xiao Y, Li G, Casiano CA, Zhang L. Effect of maternal chronic hypoxic exposure during gestation on apoptosis in fetal rat heart. Am J Physiol Heart Circ Physiol 2003; 285: H983-H990. https://doi.org/10.1152/ajpheart.00005.2003.

12. Ream M, Ray AM, Chandra R, Chikaraishi DM. Early fetal hypoxia leads to growth restriction and myocardial thinning. Am J Physiol Regul Integr Comp Physiol 2008; 295(2): R583- R595. https://doi.org/10.1152/ajpregu.00771.2007.

13. Patterson AJ, Zhang L. Hypoxia and Fetal Heart Development. Curr Mol $\begin{array}{lll}\text { Med 2010; 10(7): 653-666. } & \end{array}$ https://doi.org/10.2174/156652410792630643.

14. Ahuja $P$, Sdek $P$, MacLellan WR. Cardiac myocyte cell cycle control in development, disease, and regeneration. Physiol Rev 2007; 87(2): 521544. https://doi.org/10.1152/physrev.00032.2006

15. Paradis A, Xiao D, Zhou J, Zhang L. Endothelin-1 promotes cardiomyocyte terminal differentiation in the developing heart via heightened DNA methylation. Int J Med Sci 2014; 11(4): 373-380. https://doi.org/10.7150/ijms.7802.

16. Zubenko SI, Yan L, Zhul'kov MO, Sazonova EN, Lebed'ko OA. Effects of antenatal hypoxia on tissue homeostasis in the myocardium of albino rats: early and delayed consequences. Bulletin of Experimental Biology 
and $\quad$ Medicine 2014; 157(3): 320-323. https://www.elibrary.ru/item.asp?id=21297640.

17. Kroemer G, Mariño G, Levine B. Autophagy and the integrated stress $\begin{array}{llll}\text { response. } \quad \mathrm{Mol} \quad \mathrm{Cell} & 2010 ; & \end{array}$ https://doi.org/10.1016/j.molcel.2010.09.023.

18. Levonen AL, Hill BG, Kansanen E, Zhang J, Darley-Usmar VM. Redox regulation of antioxidants, autophagy, and the response to stress: implications for electrophile therapeutics. Free Radic Biol Med 2014; 71: 196-207. https://doi.org/10.1016/j.freeradbiomed.2014.03.025.

19. Matsui Y, Takagi H, Qu X, Abdellatif M, Sakoda H, Asano T, et al. Distinct roles of autophagy in the heart during ischemia and reperfusion: roles of AMP-activated protein kinase and Beclin 1 in mediating autophagy. Circ Res 2007; 100(6): 914-922. https://doi.org/10.1161/01.RES.0000261924.76669.36.

20. Meneghini A, Ferreira C, Abreu LC, Ferreira M, Ferreira Filho C, Valenti VE, et al. Cold stress effects on cardiomyocytes nuclear size in rats: light microscopic evaluation. Rev Bras Cir Cardiovasc 2008; 23(4): 530 533. https://doi.org/10.1590/s0102-76382008000400013

21. Valentim L, Laurence KM, Townsend PA, Carroll CJ, Soond S, Scarabelli TM, et al. Urocortin inhibits Beclin1-mediated autophagic cell death in cardiac myocytes exposed to ischaemia/reperfusion injury. $\mathrm{J} \mathrm{Mol} \mathrm{Cell}$ Cardiol 2006; 40(6): 846-852. https://doi.org/10.1016/j.yjmcc.2006.03.428.

22. Fitzpatrick CM, Shi Y, Hutchins WC, Su J, Gross GJ, Ostadal B, et al. Cardioprotection in chronically hypoxic rabbits persists on exposure to normoxia: role of NOS and KATP channels. Am J Physiol Heart Circ Physiol 2005; 288(1): H62-H68. https://doi.org/10.1152/ajpheart.00701.2004.

23. Calabró V, Litterio MC, Fraga CG, Galleano M, Piotrkowski B. Effects of quercetin on heart nitric oxide metabolism in I-NAME treated rats. Arch Biochem Biophys 2018; 647: 47-53. https://doi.org/10.1016/j.abb.2018.03.041.

24. Liu $P, X u$ B, Forman LJ, Carsia R, Hock CE. L-NAME enhances microcirculatory congestion and cardiomyocyte apoptosis during myocardial ischemia-reperfusion in rats. Shock 2002; 17(3): 185-192. https://doi.org/10.1097/00024382-200203000-00005.

25. Witkin JM, Statnick MA, Rorick-Kehn LM, Pintar JE, Ansonoff M, Chen $\mathrm{Y}$, et al. The biology of Nociceptin/Orphanin FQ (N/OFQ) related to obesity, stress, anxiety, mood, and drug dependence. Pharmacol. Ther 2014; 141(3): 283-299. https://doi.org/10.1016/j.pharmthera.2013.10.011.

26. Kim KW, Chung YJ, Han JH, Woo RS, Park EY, Seul KH et al. Nociceptin/orphanin FQ increases ANP secretion in neonatal cardiac myocytes. Life Sci 2002; 70(9): 1065-1074. https://doi.org/10.1016/s0024-3205(01)01474-6.

\section{Authors:}

Elena N. Sazonova - MD, DSc, Associate Professor, Chair of the Department of Normal and Pathological Physiology, Vice-Rector for Research, Far Eastern State Medical University; Leading Researcher, Khabarovsk Branch of the Far Eastern Scientific Center for Respiratory Physiology and Pathology - Research Institute of Maternal and Child Health Protection, Khabarovsk, Russia. https://orcid.org/0000-0002-8668-492X.

Olga A. Lebed'ko - MD, DSc, Director, Khabarovsk Branch of the Far Eastern Scientific Center for Respiratory Physiology and Pathology Research Institute of Maternal and Child Health Protection; Principal Researcher, Central Research Laboratory, Far Eastern State Medical University, Khabarovsk, Russia. https://orcid.org/0000-0002-8855-7422.

Natalya A. Tsymbalist - PhD, Associate Professor, Senior Researcher, Central Research Laboratory, Far Eastern State Medical University, Khabarovsk, Russia. https://orcid.org/0000-0003-0244-9576.

Ilya A. Gusev - Undergraduate Student, Division of Therapy, Far Eastern State Medical University, Khabarovsk, Russia. https://orcid.org/0000-00026199-4278.
Elena Yu. Samarina - MD, PhD, Associate Professor, Department of Normal and Pathological Physiology, Far Eastern State Medical University, Khabarovsk, Russia. https://orcid.org/0000-0002-2748-6923.

Yulia B. Malofey - PhD, Senior Researcher, Central Research Laboratory, Far Eastern State Medical University, Khabarovsk, Russia. https://orcid.org/0000-0001-5698-3665. 